\section{O dilema multicultural e o desafio da antropologia}

MACAGNO, Lorenzo. O dilema multicultural. Prefácio de Michel Cahen. Curitiba/Rio de Janeiro, Editora da UFPR/Graphia, 2014. 304 páginas.

\section{José Lindomar Albuquerque}

O livro de Lorenzo Macagno, O dilema multicultural, é um convite ao debate acadêmico e político sobre alguns impasses que envolvem a discussão sobre diferenças étnicas e nacionais nas heterogêneas sociedades contemporâneas. Trata-se de uma síntese criativa de um longo percurso de investigação - especialmente em Moçambique, Portugal e Brasil -, em que o tema do multiculturalismo constituiu, de maneira central ou tangencial, o horizonte de preocupação acadêmica. Como justifica o autor, não se trata, portanto, de uma reuniáo de textos escritos, mas de uma reescrita baseada no problema central em torno dos paradoxos do multiculturalismo e do lugar da própria antropologia no campo minado da diversidade, da identidade e da diferença política e cultural.

O dilema multicultural é, sobretudo, um problema político que diz respeito à própria forma de organização do Estado nacional moderno e a necessidade de "intervir e legislar" em nome do reconhecimento da diferença no interior das fronteiras nacionais. A imaginação nacional, pelo menos desde o final do século XIX, estabeleceu-se a partir do isomorfismo entre Estado, nação, povo e território. Neste modelo, a diferença interna ao território nacional deveria ser assimilada, expulsa ou, nos casos mais extremos, exterminada em nome da construção homogênea da nação (Gellner, 1996). É justamente depois dessas soluçóes mais extremadas, como no caso do Holocausto na Segunda Guerra Mundial, ou dos processos de descolonização na Ásia e na África, que a pauta da diferença cultural no interior das naçóes passa ser repensada e paulatinamente reconhecida.

Nas últimas décadas, as políticas multiculturais alimentam-se de uma gramática conceitual advinda do próprio campo da antropologia e outras ciências sociais. Com o advento dos estudos culturais e do multiculturalismo, a antropologia perdeu o monopólio da reflexão legítima sobre o conceito de cultura, que atualmente circula em um campo reflexi- vo de debate público em torno das reivindicaçóes e das políticas multiculturais. Os antropólogos são, por sua vez, interpelados a se posicionarem diante do feitiço que se virou contra os feiticeiros, ou seja, diante das visóes essencialistas de conceitos de matriz antropológica apropriados pelos grupos sociais e agências de Estado, produzindo desentendimentos, equívocos, entre outras significações. Como afirma o autor, "o desafio do dilema multicultural consiste, também, em ter de lidar com um objeto que reflete acerca da sua própria condição (multi) cultural" (p. 39). Esse lugar reflexivo, crítico e, por vezes, colaborativo da antropologia no debate e na agenda política multicultural é, sem dúvida, um dos pontos relevantes deste livro.

Lorenzo Macagno também apresenta uma crítica à noção de "reconhecimento" que permeia o debate multicultural, especialmente no campo da filosofia política nos Estados Unidos. O "falso problema" do reconhecimento parte de uma visão normativa de uma sociedade democrática fundada em noçóes de confiança, contrato, consenso e virtudes públicas. Ao problematizar essa carga valorativa, o autor pôde estender essa noção para o amplo campo observável das interaçóes sociais, em que estão presentes formas sociais variadas de hospitalidade e hostilidade, cooperação e conflito, adulação e traição. Nesse sentido, podemos reconhecer tanto um "amigo" como um "inimigo", além de saber que um "amigo" pode se tornar "inimigo" e vice-versa no jogo das relaçóes sociais. Um dos aspectos inovadores da discussão sobre reconhecimento, que merece desdobramentos futuros, diz respeito justamente ao "perturbador problema da traição” (p. 176). A defesa de uma abordagem empírica das microrrelaçóes de reconhecimento possibilitaria ainda introduzir o problema da guerra e do conflito social no debate da antropologia do político, problematizando as visóes centradas em mediaçóes culturais e negociaçôes políticas (Montero, Arruti e Pompa, 2012; Macagno, 2014).

O livro é composto por uma apresentação de Peter Fry, um prefácio de Michel Cahen, introdução, seis capítulos, conclusão e uma nota sobre os capítulos.

$\mathrm{Na}$ introdução, Lorenzo Macagno discorre sobre o "terreno pantanoso e movediço" dos dilemas e caminhos do multiculturalismo e o desafio da antropologia diante de um objeto que fala e pensa a 
cultura. $\mathrm{O}$ dilema fundamental desta arena política multicultural se estabelece entre os esforços políticos de construir e reconhecer uma "cultura pública" em comum que não elimine as diferenças e as tentaçóes étnicas que as reforçam e que podem apagar uma "comunicação mínima” entre esses mundos políticos e culturais distintos.

Os dois primeiros capítulos são dedicados a pensar as genealogias do discurso racista e as etnogenealogias do nacionalismo como elementos centrais e opostos à narrativa multicultural. A "solução" multicultural é uma resposta possível aos problemas do racismo e do nacionalismo no contexto dos Estados nacionais. Esses dois fenômenos modernos, algumas vezes entrelaçados, produzem a ideia da diferença que deve ser rechaçada (racismo) ou assimilada (nacionalismo cívico-territorial) em nome da manutenção do exclusivismo étnico ou da ilusão de uma identidade nacional homogênea. Nesse sentido, o multiculturalismo só pode ser compreendido no campo relacional de disputa política e simbólica, onde as práticas de respeito e tolerância ao "outro" e o reconhecimento da diferença podem ser reivindicadas por grupos historicamente discriminados e não reconhecidos no interior e nas margens dos Estados nacionais.

"Genealogias do racismo", primeiro capítulo, enfatiza as dimensões histórica, particular e mitológica do discurso racista e suas implicaçôes nas práticas sociais em um diálogo crítico com Foucault e com alguns clássicos da antropologia. Nessa perspectiva, o discurso racista é produto inicial das relaçóes de poder entre as classes sociais no contexto das monarquias europeias do século XVIII. A nobreza em decadência recorre às ideias de "pureza de sangue" e descendência para se contrapor ao rei e ao povo. As lutas de classes transmutam-se em "guerras de raças" e alimentam os exclusivismos étnicos e nacionais. A partir da segunda metade do século XVIII, ocorre um deslocamento da "guerra de raças" para o racismo. Tal mudança é produto de uma nova forma de poder que incide sobre a administração política do homem-espécie, ou seja, um biopoder que administra a vida da população em seu movimento de "nascimento, morte, produçâo, enfermidade” (p. 58).

No segundo capítulo, "As ilusões da nação", o autor empreende uma reflexão sobre o par imi- gração/emigração com uma porta privilegiada para pensar os fenômenos da soberania, da cidadania e do próprio multiculturalismo. De acordo com ele, "o desafio é pensar a 'estabilidade' da nação a partir da 'instabilidade' da imigração” (p. 65). A imigraçáo produz o permanente confronto entre o nacional e não nacional. É um "delator involuntário" que desestabiliza as crenças profundas e persistentes da nação como se fosse "uma grande família" ligada a laços de descendência e origem que se perdem no tempo imemoriável. Os mecanismos cotidianos de busca por cidadania e nacionalidade dos imigrantes nos países de destino revelam todos os dispositivos arbitrários que estão na base de constituiçẫo dos Estados nacionais modernos, sejam os mais centrados em uma ideia cívico-territorial ou aqueles mais ligados a elementos étnicos e linguísticos.

O capítulo "Pós-modernismo ao multiculturalismo" trata das conexóes entre as correntes pós-modernas de produçáo do conhecimento e o debate acadêmico e político em torno do multiculturalismo. Na discussão sobre modernidade e pós-modernidade, os autores nomeados como pós-modernos passaram a criticar com mais vigor os metarrelatos legitimadores, enfatizando as micronarrativas e a produção do conhecimento mais "dialógico", "polifônico" e "multivocal". Essa perspectiva tem afinidade com o debate multicultural centrado em políticas de reconhecimento de direitos, memórias e narrativas históricas de grupos específicos.

Em "As peripécias do multiculturalismo", Macagno apresenta a heterogeneidade de concepções, práticas e contextos da agenda multicultural. Primeiramente contextualiza as políticas multiculturais dos casos paradigmáticos - Canadá, Estados Unidos, Suécia e Austrália-, que passaram a ser implementadas sobretudo a partir da década de 1970. Em seguida, aborda de maneira breve o debate do multiculturalismo e do interculturalismo na América Latina, além de discutir a especificidade da agenda multicultural na Índia e a excepcionalidade do multiculturalismo português fundamentado nas atuais políticas migratórias em Portugal. Por fim, os atentados de 11 de setembro de 2001 sáo um ponto de inflexão nesse contexto, com o aumento da "islamofobia” e a crítica conservadora às políticas multiculturais. $\mathrm{O}$ autor conclui o capítulo apontando 
que o desafio atual do multiculturalismo é ultrapassar a polaridade entre as ideias "iguais, mas separados" e "juntos, mas hierarquizados". Para além da tolerância e do reconhecimento da diversidade, é preciso enfrentar o problema da desigualdade social dos grupos étnicos e nacionais.

O quinto capitulo, "O triculturalismo da nação", discute a particularidade do "multiculturalismo à brasileira", implementado a partir da segunda metade da década de 1990 com base em políticas de açóes afirmativas. Segundo Macagno, estas medidas reparadoras não foram capazes de desconstruir a narrativa nacional da "fábula das três raças" (branco, negro, indígena) e do "mito da democracia racial”. O autor distancia-se tanto dos críticos que consideram essas políticas como uma forma de "racialização" de uma sociedade profundamente híbrida e mestiça, como daqueles que as percebem como uma forma de combate ao mito ou à ideologia da democracia racial. Para ele, essas açóes podem, de fato, contribuir "para que a democracia brasileira se torne cada vez mais 'racial"' (p. 234), mas, ao mesmo tempo, continuam operando como um mito nacional persistente.

No sexto e último capítulo, "Multiculturalismo na África?”, Macagno se debruça etnograficamente sobre a experiência concreta e heterogênea dos "assimilados" em Moçambique para pensar a realidade desse país no contexto do fim da guerra civil norteado pelo embate entre a Frente de Libertação de Moçambique (Frelimo) e a Resistência Nacional Moçambicana (Renamo) e do início de uma democracia pluripartidária na década de 1990. A discussão sobre a multietnicidade, as autoridades tradicionais e as incipientes políticas educacionais de bilinguismo nesse novo contexto é permeada pelas memórias e fantasmas do passado colonial recente e pelos conflitos pós-independência entre a visão homogênea da "nação socialista" centrada no "novo homem" do governo liderado pela Frelimo e as concepçóes mais regionalistas e tribalistas que se aproximam do grupo opositor. Nesse sentido, as próprias políticas "multiculturais" do presente são muitas vezes encaradas por membros do governo e setores sociais como uma ameaça de retorno ao "tribalismo".

Em linhas gerais, Macagno busca se afastar de visóes dicotômicas sobre o dilema multicultu- ral, como as polaridades ora condenatórias, que consideram a linguagem multicultural a reafirmação de "muralhas étnicas", ora celebratórias, que imaginam essas políticas como a fórmula ideal de integração, reconhecimento e construção de uma cultura pública compartilhada. Nas lutas concretas em torno dos usos políticos da "cultura", da "etnia", da "raça", da "língua" etc., os antropólogos têm um importante papel reflexivo acerca das dinâmicas sociais, pois são capazes de pensar criticamente a relação e circulação entre a produção antropológica, a militância política multicultural e os agentes de Estado que administram as políticas de diversidade, vislumbrando os riscos dos excessos de "hibridez" e de "pureza" nas visóes apologéticas do orgulho "lusotropicalista" ou "étnico".

Por fim, o autor conclui que não cabe à teoria antropológica resolver os dilemas do multiculturalismo. Eles são parte de um campo social mais amplo de disputas materiais, políticas e simbólicas do mundo contemporâneo: "o dilema multicultural poderá ser resolvido nos mais variados terrenos, mas nunca no relatório de pesquisa, no artigo científico, na reunião acadêmica, no livro” (p. 270). Mas o que concerniria à teoria antropológica? Talvez construir caminhos, rodeios e atalhos reflexivos em direção à compreensão de algo relevante do mundo contemporâneo e do próprio lugar da antropologia diante dos dilemas e dos paradoxos da modernidade.

Em termos analíticos, os quatro primeiros capítulos abordam elementos do debate teórico nos campos da filosofia e das ciências sociais (especialmente da antropologia) ligado a temas como racismo/etnocentrismo, nação/migração, modernidade/pós-modernidade e reconhecimento/cultura. A discussão teórica e histórica de cada capítulo é parte da estratégia de pensar o multiculturalismo para além de uma agenda política e também como um problema teórico que dialoga diretamente com o conjunto de debates acadêmicos e políticos. Os dois últimos capítulos são mobilizados para discutir a questão tratada por Ernest Renan em sua conferência na Sorbonne em 1882: "O que é uma nação?" Examinam-se aqui as especificidades das memórias e dos esquecimentos, da unidade e da diferença, dos consensos e das disputas cotidianas de duas naçóes com passado colonial - Brasil e Mo- 
çambique -, o que faz uma ponte com o debate teórico do segundo capítulo. Entretanto, tendo em mente as agendas multiculturais contemporâneas, as narrativas históricas e mitológicas de ambas as naçōes não contemplam o tema da imigração, considerado relevante para pensar a naçáo e entender certas experiências nacionais multiculturais. Provavelmente, o silêncio no debate político em torno da relação entre multiculturalismo e imigração nesses países revele algo importante a ser investigado.

O debate teórico arquitetado ao longo do livro é rico em possibilidades analíticas e desdobramentos reflexivos, suscitando questôes a serem aprofundadas. Creio que a discussão sobre as diferenças e as semelhanças entre multiculturalismo e interculturalismo deveria ter sido mais contemplada, assim como a compreensão a respeito dos Estados plurinacionais da Bolívia (Schavelzon, 2014) e do Equador (Walsh, 2009). Além disso, o debate teórico sobre colonialidade, modernidade e interculturalidade na América Latina (Escobar, 2003; Walsh, 2012) poderia ter sido abordado, sobretudo quando o autor examina questôes específicas do interculturalismo. Isso poderia lançar luz sobre a relação entre colonialidade e classificaçáo racial (Quijano, 2005), o que possibilitaria problematizar os mecanismos históricos da persistência da "raça" em naçôes que, no passado, foram colônias.

\section{Bibliografia}

ESCOBAR, Arturo. (2003), "Mundos y conocimientos de otro modo: el programa de investigación de modernidad/colonialidad latinoamericano”. Tabula Rasa, 1: 51-86.

GELLNER, Ernest. (1996), "O advento do nacionalismo e sua interpretação: os mitos da nação e da classe", in Gopal Balakrishnan (org.), Um mapa da questão nacional, Rio de Janeiro, Contraponto, pp. 107-154.

MACAGNO, Lorenzo. (2014), "Uma antropologia do político?" Análise Social, 210 (1): 163-189.

MONTERO, Paula; ARRUTI, Maurício \& POMPA, Cristina. (2012), "Para uma antropologia do político", in Adrian Lavalle (org.), O horizonte da politica: questóes emergentes e agendas de pesquisa, São Paulo, Editora da Unesp/Ce- brap, pp. 1-42.

QUIJANO, Anibal. (2005), "A colonialidade do poder, eurocentrismo e América Latina", in Edgardo Lander (org.), A colonialidade do saber - eurocentrismo e ciências sociais: perspectivas latino-americanas. Buenos Aires, Clacso, pp. 107- 130.

RENAN, Ernest. (1997), "O que é uma nação". Trad. Samuel Titan Jr. Plural, 4: 154-175.

SCHAVELZON, Salvador. (2010), A Assembleia Constituinte da Bolivia: etnografia do nascimento de um Estado plurinacional. Rio de Janeiro, tese de doutorado, Programa de Pós-graduação em Antropologia Social do Museu Nacional, Universidade Federal do Rio de Janeiro.

WALSH, Catherine. (2009), Interculturalidad, Estado, sociedad: luchas (de)coloniales de nuestra época. Quito, Ediciones Abya-Yala. . (2012), "Interculturalidad y (de) colonialidad: perspectivas críticas y políticas". Visão Global, 15 (1-2): 61-74.

\section{JOSÉ LINDOMAR ALBUQUERQUE é professor de sociologia na Universidade Federal de Sáo Paulo. E-mail: joselindomar74@gmail.com.}

DOI: $10.17666 / 329506 / 2017$ 